\title{
MOŻLIWOŚCI ROLNICZEGO WYKORZYSTANIA AZOTU MINERALNEGO UWALNIANEGO Z GLEB ALUWIALNYCH
}

\begin{abstract}
Celem pracy było opracowanie metody ilościowego szacowania przyswajalnego dla runi łąkowo-pastwiskowej azotu glebowego, uwalnianego w warunkach mad żuławskich w wyniku procesów, którym podlega glebowa materia organiczna oraz możliwości jego rolniczego zagospodarowania. Ilościowe określanie uwalnianego azotu umożliwia poprawę gospodarowania tym składnikiem nawozowym w mineralnym odżywianiu się runi łąkowo-pastwiskowej co ma uzasadnione ekonomicznie a jednocześnie ogranicza jego rozpraszanie do środowiska. Badania prowadzono na Żuławach Elbląskich, na ciężkiej płytkiej madzie próchnicznej, zawierającej około 350 t glebowej materii organicznej i od 13 do $20 \mathrm{t} \mathrm{N}_{\mathrm{og}}$. W przeliczeniu na 1 ha. Przedmiotem badań była ruń łąkowa o zróżnicowanej intensywności użytkowania i nawożenia mineralnego Do określenia wydajności mineralizacji netto azotu glebowego zastosowano pośrednią metodę bilansową. Do ilościowojakościowych badań odcieków zastosowano mini lizymetry Łaukajtysa, umieszczone na każdym poletku doświadczalnym. Wykazano, że - w zależności od zróżnicowanego nawożenia NPK oraz częstotliwości koszenia - ruń łąkowa w sezonie wegetacyjnym pobrała od 80 do $170 \mathrm{~kg}$ azotu, uwalnianego wskutek mineralizacji glebowej materii organicznej. Wykazano również, że ruń łąkowa wykorzystuje do przyrostu plonu użytkowego, w zależności od intensywności użytkowania i nawożenia, od 58 do $78 \%$ ogólnej ilości wniesionego azotu mineralnego.
\end{abstract}

Słowa kluczowe: azot glebowy, mada próchniczna, gospodarka azotem mineralnym

\section{Wstęp}

Racjonalne gospodarowanie azotem mineralnym w warunkach trwałych użytków zielonych jest podstawowym czynnikiem decydującym o efektywności ekonomicznej, a jednocześnie może ograniczać negatywny wpływu produkcji rolnej na środowisko. Precyzyjne wykorzystanie azotu mineralnego przez ruń

\footnotetext{
${ }^{1}$ Jerzy Terlikowski, Państwowa Wyższa Szkoła Zawodowa w Elblągu, ul. Grunwaldzka 137, 82-300 Elbląg, tel. 502587632, j.terlikowski@op.pl

2 Instytut Technologiczno-Przyrodniczy, Żuławski Ośrodek Badawczy w Elblągu
} 
łąkowo-pastwiskową skłania do poszukiwania metod umożliwiających ilościowe określanie dostępnego azotu. Do osiągnięcia poprawy gospodarowania azotem na użytkach zielonych, duże znaczenie mogą mieć informacje o jego ilości uwalnianej w procesie mineralizacji glebowej materii organicznej. Dla potrzeb pokarmowych runi łąkowej ważna jest ta ilość uwalnianego azotu glebowego, która jest pobierana przez biomasę plonu użytkowego (tzw. mineralizacja netto). Jest to różnica pomiędzy mineralizacją brutto a immobilizacją mikrobiologiczną i azotem pobieranym przez darń oraz jego stratami do środowiska [1,9].

$\mathrm{W}$ racjonalnym nawożeniu istotne jest nie tylko rozpoznanie potrzeb pokarmowych (oblicza się je, mnożąc zakładany plon przez pobranie jednostkowe), lecz także w miarę dokładne określenie dostępności tego składnika z gleby.

Ruń łąkowa swoje potrzeby pokarmowe zaspokaja w wyniku stosowania nawożenia, jak i z zasobów znajdujących się w glebie oraz opadu suchego i mokrego [7]. Generalnie potrzeby nawozowe względem nawozów mineralnych oblicza się, odejmując od potrzeb pokarmowych ilość składnika, jaką rośliny będą miały do dyspozycji z zasobów glebowych (do tej puli zalicza się zarówno składnik rodzimy - pochodzący z mineralizacji glebowej materii organicznej, jak i składnik, który pochodzi z rozkładu zastosowanych nawozów naturalnych i organicznych, a także azot cząsteczkowy (atmosferyczny) związany przez bakterie symbiotyczne (symbioza z roślinami motylkowymi) i wolno żyjące w glebie.

Na mineralizację azotu składa się zespół procesów prowadzących do powstawania amoniaku lub azotu amonowego. Ma to zasadnicze znaczenie dla roślin, ponieważ azot amonowy jest formą bezpośrednio pobieraną przez ich system korzeniowy, a także łatwo przekształca się dalej w azotany, które są jeszcze łatwiej wykorzystywane przez rośliny. Ustalenie zawartości azotu mineralnego jest rezultatem równowagi dwóch przeciwstawnych procesów: mineralizacji i immobilizacji. O jej poziomie decyduje skład materii organicznej, a głównie stosunek zawartości węgla i azotu. Ilość azotu immobilizowana przez drobnoustroje jest tym większa, im więcej znajduje się w środowisku łatwo dostępnych materiałów energetycznych - węglowodanów. Jeśli rozkładane resztki roślinne zawierają dużo węglowodanów, a obok tego mało połączeń azotowych, wtedy prawie cały azot tych związków jest przetwarzany na białko drobnoustrojów. Gdy natomiast w rozkładającej się glebowej materii organicznej stosunek węglowodanów do azotu jest wąski to przeważa proces mineralizacji azotu i duża jego część przechodzi w sole amonowe [2].

Podatność organicznych powiązań azotu na mineralizację jest zróżnicowana i zależy od warunków glebowo-wodnych i tempa rozkładu każdego z komponentów glebowej materii organicznej [4]. Wydajność mineralizacji glebowej materii organicznej może przebiegać w różnym tempie. Zależy to od zmiany warunków red-ox. Od mineralizacji azotu związanego $\mathrm{z}$ materią organiczną w glebie zależy jego wykorzystanie przez ruń oraz straty w wyniku wymywania $\mathrm{N}-\mathrm{NO}_{3}$. Kobuz [2] podaje, że w glebowej materii organicznej znajduje się ponad 
90\% związanego azotu. Przemiany tej materii mogą więc dostarczać azot mineralny potrzebny do mineralnego odżywiania się roślin. Jednak ten proces jest kontrolowany przez temperaturę, wilgotność oraz ilość i jakość glebowej materii organicznej jako substratu mikrobiologicznego. Według Smith'a i Paul'a [8], badających dynamikę mineralizacji masy organicznej w glebie, w ekosystemach łąkowych zostaje zmineralizowane w ciągu roku od 95 do $380 \mathrm{~kg} \mathrm{~N} \cdot \mathrm{ha}^{-1}$.

Duże znaczenie ekonomiczne i ekologiczne może mieć oszacowanie puli azotu mineralnego uwalnianego $\mathrm{w}$ sezonie wegetacyjnym $\mathrm{z}$ glebowej materii organicznej mineralnych w warunkach gleb łąkowych.

Celem pracy było opracowanie metody ilościowego szacowania przyswajalnego dla runi łąkowo-pastwiskowej azotu glebowego, uwalnianego w warunkach mad żuławskich w wyniku dynamiki procesów, którym podlega glebowa materia organiczna oraz możliwości jego rolniczego zagospodarowania.

\section{Materiał i metody BADAŃ}

Badania prowadzono w latach 2008-2011 w miejscowości Helenowo na Żuławach Elbląskich, na doświadczeniu, założonym w 2007 roku metodą losowanych bloków w czterech powtórzeniach, według schematu przedstawionego w tabeli 1 . Doświadczenie umieszczone było na łące poddanej renowacji metodą pełnej uprawy w 2001 roku.

Tabela 1. Schemat doświadczenia założonego w Helenowie

Table 1. Scheme of experiment at Helenowo

\begin{tabular}{|c|c|c|c|c|}
\hline $\begin{array}{c}\text { Użytko- } \\
\text { wanie }\end{array}$ & Kombinacja & $\begin{array}{c}\text { Ilośćć } \\
\text { pokosów }\end{array}$ & Nawożenie & Dawki nawozów \\
\hline \multirow{5}{*}{$\begin{array}{l}\text { Trwały } \\
\text { użytek } \\
\text { zielony } \\
\text { (łąka } \\
\text { trwała) }\end{array}$} & 1 & 1 & 0 & \multirow{5}{*}{$\begin{array}{l}\mathrm{N}-60 \mathrm{~kg} \cdot \mathrm{ha}^{-1} \text { pod odrost; } \\
\mathrm{P}-40 \mathrm{~kg} \cdot \mathrm{ha}^{-1} ; \\
\mathrm{K}-50 \mathrm{~kg} \cdot \mathrm{ha}^{-1} \text { wiosną } \\
+50 \mathrm{~kg} \cdot \mathrm{ha}^{-1} \text { w połowie } \\
\text { okresu wegetacyjnego }\end{array}$} \\
\hline & 2 & 2 & 0 & \\
\hline & 3 & 2 & $\mathrm{PK}$ & \\
\hline & 4 & 3 & PK & \\
\hline & 5 & 3 & NPK & \\
\hline
\end{tabular}

Ruń charakteryzowała się uproszczonym składem gatunkowym, w którym dominowały: kupkówka pospolita (Dactylis glomerata), tymotka łąkowa (Phleum pratense), z niewielkim udziałem kostrzewy łąkowej (Festuca pratensis), perzu właściwego (Elymus repens) i wiechliny łąkowej (Poa pratensis). Trawy stanowiły łącznie około 75-85\% pokrycia, rośliny dwuliścienne - około $25 \%$, a rośliny motylkowate występowały w runi w ilościach śladowych.

Łąka była położona $0,40 \mathrm{~m}$ p.p.m. na madzie bardzo ciężkiej płytkiej podścielonej piaskiem luźnym [8F bc.pl]. Poziom próchniczny stanowi warstwa gleby o miąższości $45-55 \mathrm{~cm}$. Wybrane właściwości fizyko-chemiczne gleby podano w tabeli 2. 
Tabela 2. Charakterystyka fizykochemiczna gleby

Table 2. Physical and chemical properties of soil

\begin{tabular}{|c|c|c|c|c|c|c|}
\hline \multirow[t]{2}{*}{$\begin{array}{c}\text { Grębokość } \\
{[\mathrm{cm}]}\end{array}$} & \multirow[t]{2}{*}{$\begin{array}{c}\text { Gęstość } \\
\text { objętościowa } \\
{\left[\mathrm{g} \cdot \mathrm{cm}^{-1}\right]}\end{array}$} & \multirow[t]{2}{*}{$\mathbf{C}[\%]$} & \multirow[t]{2}{*}{$\begin{array}{c}\mathbf{p H} \\
{[1 \mathrm{~N} \mathrm{KCl}]}\end{array}$} & \multicolumn{3}{|c|}{$\begin{array}{c}\text { Zasobność w przyswajalne } \\
\text { składniki } \\
{\left[\mathrm{mg} \cdot \mathrm{kg}^{-1} \mathrm{~s} . \mathrm{m} . \text { gleby }\right]}\end{array}$} \\
\hline & & & & $P$ & $\mathrm{~K}$ & $\mathrm{Mg}$ \\
\hline \multirow{2}{*}{$0-20$} & $\begin{array}{c}1,295 \text { (blok } \\
\mathrm{AiB})\end{array}$ & 4,00 & 4,88 & 42 & 411 & 50 \\
\hline & $\begin{array}{c}1,269 \text { (blok } \\
\text { CiD) }\end{array}$ & 4,04 & 5,29 & 31 & 327 & 52 \\
\hline \multirow{2}{*}{$21-40$} & $\begin{array}{c}1,315 \text { (blok } \\
\mathrm{AiB})\end{array}$ & 3,88 & 5,36 & 45 & 206 & 52 \\
\hline & $\begin{array}{l}1,307 \text { (blok } \\
\text { CiD) }\end{array}$ & 3,95 & 5,32 & 39 & 243 & 48 \\
\hline \multirow{2}{*}{$41-60$} & $\begin{array}{c}1,307 \text { (blok } \\
\text { AiB) }\end{array}$ & 2,75 & 6,31 & 43 & 111 & 17 \\
\hline & $\begin{array}{c}1,378 \text { (blok } \\
\text { CiD) }\end{array}$ & 2,84 & 6,33 & 23 & 79 & 21 \\
\hline
\end{tabular}

Średnie dobowe temperatury $\mathrm{z}$ okresu wegetacji w latach $2008-2010$ były zbliżone do wartości z wielolecia. Natomiast w roku 2011 średnia dobowa temperatura okresu wegetacji była wyższa o $2,8^{\circ} \mathrm{C}$ od średniej z wielolecia. Suma opadów z okresów wegetacji 2008-2010 była również zbliżona do średniej $\mathrm{z}$ wielolecia, w roku 2011 suma opadów w okresie wegetacji była niższa od opadów z wielolecia o około $129 \mathrm{~mm}$, to jest o około $27 \%$.

Głębokość zalegania zwierciadła wody gruntowej wahała się w okresie prowadzonych badań od około $35-40 \mathrm{~cm}$ wiosną przed ruszeniem wegetacji i obniżała się w okresie od maja do końca wegetacji do 150-155 cm.

Doświadczenie zostało wyposażone w minilizymetry Laukajtysa do ilościowo-jakościowych badań odcieków. Zawartość mineralnych form azotu N$\mathrm{NO}_{3}$ i N-NH $\mathrm{N}_{4}$ w glebie (po ekstrakcji w $1 \%$ wyciągu $\mathrm{K}_{2} \mathrm{SO}_{4}$ ) oraz w odciekach wodnych oznaczano metodą kolorymetryczną.

Zawartość azotu ogólnego w glebie i roślinności oznaczano metodą Kjeldahla.

Przyswajalne formy fosforu i potasu w glebie oznaczono metodą EgneraRiehma, a magnezu - metodą Schachtschabela wg odczytu z AAS. Węgiel w glebie oznaczono metodą Tiurina, a $\mathrm{pH}$ - potencjometrycznie w $1 \mathrm{n} \mathrm{KCl}$.

Do ilościowego określenia wydajności mineralizacji netto azotu glebowego zastosowano pośrednią metodę bilansową. W bilansie uwzględniono:

- po stronie przychodów:

- zawartość azotu mineralnego w glebie wiosną przed ruszeniem wegetacji,

- azot nawozowy,

- azot biologiczny [6],

- azot z opadu atmosferycznego mokrego i suchego [5]. 
- po stronie rozchodów:

- azot wyniesiony z plonem,

- azot w odciekach przemieszczający się poza strefę korzeniową w okresie wegetacji,

- azot w glebie po zakończeniu wegetacji.

Pomimo wielu badań nie opracowano bezpośredniej metody służącej do ilościowego oznaczania azotu glebowego, który ulega przemianom w formy mineralne pobierane przez ruń łąkowo-pastwiskową [3, 9]. Natomiast pośrednią metodą bilansową można oszacować tylko tą część uwolnionego azotu z glebowej materii organicznej, która została pobrana przez run i wbudowana w biomasę plonu użytkowego, a więc umożliwia określenie uwalnianej puli azotu z glebowej materii organicznej, która może mieć istotne znaczenie gospodarcze i powinna być uwzględniana w ustalaniu dawki nawożenia azotem.

Tabela 3. Warunki meteorologiczne w okresie prowadzenia badań

Table 3. Meteorological conditions during experiment

\begin{tabular}{|c|c|c|c|c|c|c|c|c|c|c|c|c|c|c|}
\hline Miesiąc & I & II & III & IV & V & VI & VII & VIII & IX & $\mathbf{X}$ & XI & XII & \multicolumn{2}{|c|}{$\begin{array}{c}\text { Średnia }\left[{ }^{0} \mathrm{C}\right] / \\
\text { Suma }[\mathrm{mm}]\end{array}$} \\
\hline Rok & & & & & & & & & & & & & IV-IX & Rok \\
\hline \multicolumn{15}{|c|}{ Temperatura $\left[{ }^{\circ} \mathrm{C}\right]$} \\
\hline $2008^{* * *}$ & 1,3 & 3,7 & 3,8 & 8,3 & 13,0 & 17,2 & 18,4 & 18,2 & 14,3 & 8,0 & 4,5 & 1,1 & 14,9 & 9,3 \\
\hline $2009^{* * *}$ & $-2,0$ & $-0,5$ & 2,6 & 10,0 & 12,5 & 15,0 & 19,1 & 18,8 & 15,1 & 15,1 & 5,9 & $-1,1$ & 15,1 & 8,5 \\
\hline $2010^{* * *}$ & $-7,6$ & $-2,0$ & 3,0 & 7,7 & 11,5 & 16,4 & 21,7 & 19,8 & 13,4 & 13,4 & 4,8 & $-6,4$ & 15,1 & 7,4 \\
\hline $2011^{* *}$ & $-0,9$ & $-5,2$ & 2,5 & 13,2 & 13,0 & 17,6 & 18,6 & 18,5 & 15,0 & 15,0 & 4,2 & 3,0 & 16,0 & 9,1 \\
\hline $\begin{array}{l}\text { 1971- } \\
1995^{*}\end{array}$ & $-1,9$ & $-1,6$ & 1,8 & 6,2 & 11,9 & 15,0 & 17,0 & 16,7 & 12,6 & 8,1 & 3,0 & 0,0 & 13,2 & 7,4 \\
\hline \multicolumn{15}{|c|}{ Opady [mm] } \\
\hline $2008^{* * *}$ & 35,0 & 13,7 & 31,4 & 28,8 & 16,6 & 51,0 & 83,7 & 90,7 & 32,0 & 46,2 & 24,5 & 18,0 & 302,8 & 471,6 \\
\hline $2009 * *$ & 24,1 & 15,5 & 55,2 & 2,3 & 62,3 & 114,8 & 114,3 & 18,8 & 22,4 & 91,3 & 28,4 & 24,8 & 334,9 & 574,2 \\
\hline $2010^{* * *}$ & 0,0 & 19,8 & 21,7 & 13,2 & 81,3 & 13,5 & 68,0 & 108,8 & 44,6 & 10,3 & 83,6 & 15,1 & 329,4 & 479,9 \\
\hline $2011 * *$ & 42,6 & 18,0 & 11,1 & 1,0 & 9,0 & 46,6 & 105,2 & 36,9 & 11,6 & 36,4 & 8,0 & 26,3 & 210,3 & 352,7 \\
\hline $\begin{array}{l}1971- \\
1995^{*}\end{array}$ & 17,3 & 12,7 & 16,6 & 22,6 & 40,4 & 67,6 & 66,7 & 71,5 & 70,1 & 47,9 & 38,5 & 0,8 & 338,9 & 484,6 \\
\hline
\end{tabular}

*- dane z Oddziału Morskiego IMGW w Gdyni;

**- dane ze stacji agrometeorologicznej ITP ŻOB w Helenowie

\section{Wyniki i dyskusja}

Ładunki azotu, przedstawione w tabeli 4, odprowadzane wraz z wodą infiltrującą poza strefę korzeniową wskazują, że znacznie większe straty $\mathrm{N}_{\min }$. występują w okresie poza wegetacyjnym. Duże zróżnicowanie ilości odpływającego azotu mineralnego w odciekach w głąb profilu glebowego wystąpiło również pomiędzy badanymi obiektami. 
Bilanse azotu przeprowadzone w latach 2008-2011 i przedstawione w tabelach 5-8 wykazały, że ilość pobranego przez ruń azotu glebowego jest uzależniona od warunków glebowo-wodnych jak również od częstotliwości koszenia i sposobu nawożenia. Ponad to na pulę azotu glebowego dostępnego składa się wiele źródeł, które w mniejszym lub większym stopniu są dostępne dla runi łąkowej. Jednocześnie trzeba zaznaczyć, że azot znajdujący się w glebie podlega wielu przemianom, które decydują o tym, że ilość tego składnika dostępnego dla roślin w zależności od warunków może się dość drastycznie zmieniać. Ocenie poddano wyniki średnie salda bilansu $\mathrm{N}$ z czterech lat badań.

Tabela 4. Ładunki azotu mineralnego $\left(\mathrm{N}-\mathrm{NO}_{3}+\mathrm{N}-\mathrm{NH}_{4}\right)$ odprowadzane wraz z wodą infiltrującą poza strefę korzeniową runi $\left[\mathrm{kg} \cdot \mathrm{ha}^{-1}\right]$. Helenowo $2007-2012$

Table 4. Loads of mineral nitrogen $\left(\mathrm{N}-\mathrm{NO}_{3}+\mathrm{N}-\mathrm{NH}_{4}\right)$ in leaching water out of the sward root zone. Helenowo 2007 - 2012

\begin{tabular}{|c|c|c|c|c|c|}
\hline \multirow{2}{*}{$\begin{array}{c}\text { Okresy prowadzonych pomiarów } \\
\text { odcieków }\end{array}$} & \multicolumn{5}{|c|}{ Obiekty } \\
\hline & 1 & 2 & 3 & 4 & 5 \\
\hline od 16.XI.2007 do 17.IV.2008 & 2,1 & 2,3 & 2,7 & 3,3 & 3,4 \\
\hline od 07.IV.2008 do 10.XI.2008 & 0,6 & 1,6 & 2,0 & 1,1 & 0,9 \\
\hline od 11.XI.2008 do 28.IV.2009 & 204 & 242 & 196 & 131 & 268 \\
\hline od 29.IV.2009 do 09.XI.2009 & 21 & 5 & 9 & 2 & 8 \\
\hline od 10.XI.2009 do 24.III.2010 & 94 & 50 & 54 & 71 & 196 \\
\hline od 25.III.2010 do 08.X.2010 & 11 & 17 & 10 & 47 & 30 \\
\hline od 09.X.2010 do 22.III.2011 & 15 & 15 & 63 & 76 & 115 \\
\hline od 23.III.2011 do 03.XI.2011 & 25 & 82 & 64 & 65 & 83 \\
\hline od 04.XI.2011 do 22.III.2012 & 91 & 73 & 171 & 177 & 203 \\
\hline od 23.III.2012 do 03.XI.2012 & 32 & 75 & 83 & 126 & 131 \\
\hline $\begin{array}{l}\text { Średnia ilość ładunków } \mathbf{N}_{\text {min }}: \\
\text { z okresów wegetacji } \\
\text { spoza okresów wegetacji }\end{array}$ & $\begin{array}{l}18 \\
81\end{array}$ & $\begin{array}{l}36 \\
76\end{array}$ & $\begin{array}{l}34 \\
97\end{array}$ & $\begin{array}{l}48 \\
92\end{array}$ & $\begin{array}{c}51 \\
157\end{array}$ \\
\hline
\end{tabular}

W użytkowaniu jednokośnym (bez nawożenia mineralnego) ruń, w przeliczeniu na 1 ha, pobrała średnio tylko $80 \mathrm{~kg}$ azotu glebowego. Zwiększenie częstotliwości koszenia do dwóch pokosów w sezonie wegetacyjnym (także bez stosowania NPK) wpłynęło na znacznie lepszą możliwość wykorzystanie azotu glebowego, ponieważ ruń pobrała z gleby około $150 \mathrm{~kg} \cdot \mathrm{ha}^{-1}$. Zastosowanie nawożenia PK spowodowało wzrost pobrania azotu z gleby do około $170 \mathrm{~kg} \cdot \mathrm{ha}^{-1}$. Przy 3.kośnym użytkowaniu i nawożeniu PK run pobrała około $160 \mathrm{~kg} \cdot \mathrm{ha}^{-1}$. Wynika stąd, że najbardziej racjonalne wykorzystanie $\mathrm{N}_{\text {gleb., }}$ w warunkach łąki trwałej położonej na płytkiej bardzo ciężkiej madzie próchnicznej, można uzyskać przy dwu- i trzykrotnym użytkowaniu i ograniczeniu nawożenia mineralnego do fosforu i potasu.

Nawożenie runi azotem $\left(3 \times 60 \mathrm{~kg} \mathrm{~N} \cdot \mathrm{ha}^{-1}\right.$ pod odrost) było przyczyną pogorszenia wykorzystania $\mathrm{N}_{\text {gleb.; }}$; ruń wykorzystała tylko około $104 \mathrm{~kg} \mathrm{~N}_{\text {gleb }}$ w przeliczeniu na 1 ha $^{-1}$. 
Z uwagi na przeznaczenie runi użytków zielonych do produkcji pasz objętościowych, ich jakość odgrywa tu szczególną rolę. Zatem w produkcji pasz pod uwagę należy brać 3.kośne użytkowanie, które gwarantuje ich dobrą wartość pastewną. Jednakże łączna, dostępna pula azotu mineralnego pochodzącego ze stosowanych nawozów mineralnych łącznie z azotem glebowym okazała się być ilością nadmierną w stosunku do wymagań pokarmowych runi łąkowe.

Tabela 5. Bilans azotu mineralnego na łące trwałej w 2008 roku

Table 5. Balance of mineral nitrogen on permanent meadow in 2008

\begin{tabular}{|l|c|c|c|c|c|}
\hline \multirow{2}{*}{ Składnik bilansu } & \multicolumn{5}{c|}{ Obiekty } \\
\cline { 2 - 7 } & 1 & 2 & 3 & 4 & 5 \\
\hline Wniesiono: & \multicolumn{7}{c|}{} \\
- Retencja wiosenna (1) & 64 & 78 & 60 & 65 & 62 \\
- Nawozy mineralne (2) & - & - & - & - & 180 \\
- N z opadów (3) & 10 & 10 & 10 & 10 & 10 \\
- N biologiczny (4) & 20 & 20 & 20 & 20 & 20 \\
\hline Razem wniesiono: (5) & $\mathbf{9 4}$ & $\mathbf{1 0 8}$ & $\mathbf{9 0}$ & $\mathbf{9 5}$ & $\mathbf{2 7 2}$ \\
\hline Wyniesiono: & \multicolumn{7}{|c|}{} \\
- z plonem (6) & 122 & 221 & 269 & 254 & 352 \\
- retencja jesienna (7) & 60 & 54 & 50 & 63 & 60 \\
- N w odciekach (8) & 1 & 2 & 2 & 1 & 1 \\
\hline Razem wyniesiono: (9) & $\mathbf{1 8 3}$ & $\mathbf{2 7 7}$ & $\mathbf{3 2 1}$ & $\mathbf{3 1 8}$ & $\mathbf{4 1 3}$ \\
\hline N $_{\text {gleb }}$ pobrany przez ruńy [6-(2+3+4)] & 92 & 191 & 239 & 224 & 142 \\
\hline - N z inkubacji różnicowej (5) & 4 & 10 & -3 & 18 & 58 \\
\hline \% pobranego N przez ruń do N wyniesionego & 67 & 80 & 84 & 80 & 85 \\
\hline
\end{tabular}

Tabela 6. Bilans azotu mineralnego na łące trwałej w 2009

Table 6. Balance of mineral nitrogen on permanent meadow in 2009

\begin{tabular}{|l|c|c|c|c|c|}
\hline \multirow{2}{*}{ Składnik bilansu } & \multicolumn{5}{c|}{ Obiekty } \\
\cline { 2 - 7 } & 1 & 2 & 3 & 4 & 5 \\
\hline Wniesiono: & \multicolumn{7}{|c|}{} \\
- Retencja wiosenna (1) & 66 & 80 & 58 & 70 & 65 \\
- Nawozy mineralne (2) & - & - & - & - & 180 \\
- N z opadów (3) & 10 & 10 & 10 & 10 & 10 \\
- N biologiczny (4) & 20 & 20 & 20 & 20 & 20 \\
\hline Razem wniesiono: (5) & $\mathbf{9 6}$ & $\mathbf{1 1 0}$ & $\mathbf{8 8}$ & $\mathbf{1 0 0}$ & $\mathbf{2 7 5}$ \\
\hline Wyniesiono: & \multicolumn{7}{|c|}{} \\
- z plonem (6) & 181 & 238 & 261 & 192 & 334 \\
- retencja jesienna (7) & 47 & 61 & 57 & 44 & 47 \\
- N w odciekach (8) & 21 & 5 & 9 & 2 & 8 \\
\hline Razem wyniesiono: (9) & $\mathbf{2 4 9}$ & $\mathbf{3 0 4}$ & $\mathbf{3 2 7}$ & $\mathbf{2 3 8}$ & $\mathbf{3 9 9}$ \\
\hline N $_{\text {gleb } \cdot \text { pobrany przez ruń [6-(2+3+4)] }}$ & 151 & 208 & 231 & 162 & 134 \\
\hline - N z inkubacji różnicowej & 25 & 43 & 40 & 12 & 63 \\
\hline \% pobranego N przez ruń do N wyniesionego & 72 & 78 & 80 & 81 & 84 \\
\hline
\end{tabular}


Tabela 7. Bilans azotu mineralnego na łące trwałej w 2010

Table 7. Balance of mineral nitrogen on permanent meadow in 2010

\begin{tabular}{|c|c|c|c|c|c|}
\hline \multirow{2}{*}{ Składnik bilansu } & \multicolumn{5}{|c|}{ Obiekty } \\
\hline & 1 & 2 & 3 & 4 & 5 \\
\hline Wniesiono: & & & & & \\
\hline - Retencja wiosenna (1) & 64 & 77 & 66 & 74 & 67 \\
\hline - Nawozy mineralne (2) & - & - & - & - & 180 \\
\hline - N z opadów (3) & 10 & 10 & 10 & 10 & 10 \\
\hline - N biologiczny (4) & 20 & 20 & 20 & 20 & 20 \\
\hline Razem wniesiono: (5) & 94 & 107 & 96 & 104 & 277 \\
\hline Wyniesiono: & & & & & \\
\hline $\begin{array}{l}\text { - z plonem (6) } \\
\text { - retencja jesienna (7) }\end{array}$ & $\begin{array}{l}61 \\
67\end{array}$ & $\begin{array}{c}135 \\
66\end{array}$ & $\begin{array}{c}132 \\
61\end{array}$ & $\begin{array}{c}153 \\
63\end{array}$ & $\begin{array}{c}277 \\
63\end{array}$ \\
\hline - N w odciekach (8) & 11 & 17 & 10 & 47 & 30 \\
\hline Razem wyniesiono: (9) & 139 & 218 & 203 & 263 & 370 \\
\hline $\mathrm{N}_{\text {gleb }}$ pobrany przez ruń $[6-(2+3+4)]$ & 31 & 105 & 102 & 123 & 67 \\
\hline - N z inkubacji różnicowej & -5 & 5 & 17 & -9 & -35 \\
\hline$\%$ pobranego $\mathrm{N}$ przez ruń do $\mathrm{N}$ wyniesionego & 44 & 62 & 65 & 58 & 75 \\
\hline
\end{tabular}

Tabela 8. Bilans azotu mineralnego na łące trwałej w 2011

Table 8. Balance of mineral nitrogen on permanent meadow in 2011

\begin{tabular}{|l|c|c|c|c|c|}
\hline \multirow{2}{*}{ Składnik bilansu } & \multicolumn{5}{|c|}{ Obiekty } \\
\cline { 2 - 7 } & 1 & 2 & 3 & 4 & 5 \\
\hline Wniesiono: & \multicolumn{7}{|c|}{} \\
- Retencja wiosenna (1) & 67 & 76 & 72 & 74 & 67 \\
- Nawozy mineralne (2) & - & - & - & - & 180 \\
- N z opadów (3) & 10 & 10 & 10 & 10 & 10 \\
- N biologiczny (4) & 20 & 20 & 20 & 20 & 20 \\
\hline Razem wniesiono: (6) & $\mathbf{9 7}$ & $\mathbf{1 0 6}$ & $\mathbf{1 0 2}$ & $\mathbf{1 0 4}$ & $\mathbf{2 7 7}$ \\
\hline Wyniesiono: & \multicolumn{7}{|c|}{} \\
- z plonem (7) & 81 & 125 & 133 & 165 & 281 \\
- retencja jesienna (8) & 64 & 68 & 54 & 69 & 60 \\
- N w odciekach (9) & 25 & 82 & 64 & 65 & 83 \\
\hline Razem wyniesiono: (10) & $\mathbf{1 7 0}$ & $\mathbf{2 7 5}$ & $\mathbf{2 5 1}$ & $\mathbf{2 9 9}$ & $\mathbf{4 2 4}$ \\
\hline N $_{\text {glebyyyyy} \cdot \text { pobrany przez ruń [7-(2+3+4)] }}$ & 51 & 95 & 103 & 135 & 71 \\
\hline - N z inkubacji różnicowej (5) & 56 & 22 & 16 & 42 & 89 \\
\hline \% pobranego N przez ruń do N wyniesionego & 48 & 45 & 53 & 55 & 66 \\
\hline
\end{tabular}

Znamienne może być również wykorzystanie metody bilansowej do porównania azotu mineralnego pobranego przez ruń z azotem mineralnym wniesionym. Wartości średnie \% wykorzystanie azotu wniesionego do pobranego wykazały, że w użytkowaniu ekstensywnym (1 pokos w sezonie, bez stosowania nawożenia) wykorzystanie azotu wniesionego wyniosło 58\%. Przy użytkowaniu dwukośnym w sezonie wegetacyjnym bez stosowania nawozów mineralnych wykorzystanie azotu wniesionego wynosiło 66\%, a zastosowanie nawożenia PK poprawiło to wykorzystanie do $71 \%$. Przy 3.kośnym użytkowaniu z nawoże- 
niem PK wykorzystanie $\mathrm{N}_{\min } \mathrm{W}$ stosunku do $\mathrm{N}$ wniesionego było zbliżone do runi użytkowanej dwukośnie i nawożonej PK.

Natomiast w użytkowaniu 3-kośnym i przy nawożeniu NPK - wykorzystanie $\mathrm{N}_{\min }$ było najwyższe $\mathrm{i} w$ porównaniu do wniesionego, ruń pobrała $78 \% \mathrm{~N}_{\min }$. Wyniki badań sugerują, że po uwzględnieniu w bilansie dostępnego dla runi azotu z naturalnych źródeł, nawożenie azotem mineralnym, uzupełniające pokarmowe wymagania runi łąkowej, nie powinno, w warunkach bardzo ciężkich, płytkich mad próchnicznych, przekraczać $100 \mathrm{~kg} \mathrm{~N} \cdot \mathrm{ha}^{-1} \cdot \mathrm{rok}^{-1}$.

\section{Wnioski}

W podsumowaniu 4-letnich badań obejmujących gospodarowanie azotem mineralnym na aluwialnych glebach żuławskich, w których zastosowano metodę bilansową ,na poziomie pola”, można przedstawić następujące wnioski:

1. Wymagania pokarmowe runi łąkowej na azot, w warunkach ciężkich płytkich mad próchnicznych, mogą być pokrywane $\mathrm{z}$ azotu glebowego w ilości około $100 \mathrm{~kg} \mathrm{~N} \cdot \mathrm{ha}^{-1}$.

2. Wykazano, przydatność metody bilansowej „na poziomie pola” do ilościowego określaniu azotu glebowego netto pobieranego przez ruń łąkową i wbudowaną w plon gospodarczy.

3. Metoda bilansowa „na poziomie pola" może stanowić narzędzie do kontrolowania gospodarki azotem w siedliskach łąk położonych na glebach mineralnych oraz do opracowania nowych zasad gospodarowania azotem mineralnym $\mathrm{z}$ uwzględnieniem puli azotu dostarczanego runi w wyniku dynamiki przemian, jakim podlega glebowa materia organiczna w mineralnych glebach ląkowych.

\section{Literatura}

[1] Burzyńska I.: Migracja składników mineralnych i węgla organicznego do wód gruntowych w warunkach zróżnicowanego użytkowania łąk na glebach mineralnych. Woda-Środowisko-Obszary Wiejskie. Rozprawy naukowe i monografie nr 35, Wydawn. ITP, Falenty 2013, ss. 92. ISSN 1644-1095.

[2] Kobuz J.: Rola mikroorganizmów w przemianach azotu w glebie. Zesz. Probl. Post. Nauk Roln. z. 440, 1996, s. 151-173.

[3] Okruszko H.: Zasady nawożenia gleb torfowych. W: Gospodarowanie na glebach torfowych w świetle 40-letniej działalności Zakładu Doświadczalnego Biebrza. Bibl. Wiad. IMUZ 77, 1991, s. 87-103.

[4] Paul E.A., Clark F.E.: Mikrobiologia i biochemia wód. Wydawn. UMC-S. Lublin 2000, ss 400.

[5] Raport WIOŚ Olsztyn 2014.

[6] Sapek A.: Udział rolnictwa w zanieczyszczaniu wody składnikami nawozowymi. Zesz. Edukac. Nr 1. Wydawn. IMUZ, Falenty 2006, s. 9-33. 
[7] Sapek A., Nawalany P.: Ładunek składników nawozowych wnoszonych z opadem atmosferycznym na powierzchnię ziemi na przykładzie pól doświadczalnych w Falentach. Woda-Środowisko-Obszary Wiejskie, t. 6 z. specj. (17), s. 23-27.

[8] Smith J.L., Paul E.A.: The significance of soil microbial biomass estimations. Soil Biochem. 6, 1990, s. 357-392.

[9] Terlikowski J.: Identyfikacja zagrożeń środowiska wynikająca z wadliwej gospodarki azotem na okresowo posusznych łąkach wiechlinowo-wyczyńcowych w warunkach gleb murszowatych. Zesz. Probl. Post. Nauk Roln. z. 505, 2005, s. 477-484.

\title{
POSSIBILITIES OF AGRICULTURAL UTILIZATION OF MINERAL NITROGEN REALIZED FROM ALLUVIAL SOILS
}

\begin{abstract}
S u m m a r y
The aim of the works was elaboration of method to estimate amount of nitrogen which is realized from soil organic matter in alluvial soils during mineralization process. Knowledge of the amount of realized nitrogen enables better nitrogen management and in consequence may limit its dispersion in the environment. The investigations were carried out in Żuławy region on heavy, shallow humic alluvial soil in which content of soil organic matter (SOM) was about $350 \mathrm{t}$ and 13$20 \mathrm{t}$ of organic nitrogen $\left(\mathrm{N}_{\text {org. }}\right)$ per 1 ha. Meadow sward fertilized with different mineral fertilizers and mown with different frequency was the subject of investigation. Indirect balance method was used to estimate the efficiency of net soil nitrogen mineralization. Łaukajtys' minilysimeters were installed on each trial plot to collect leakage for chemical analysis. It was shown that meadow sward absorbed $80-170 \mathrm{~kg}$ of nitrogen coming from SOM mineralization and the amount depended on intensity of utilization. It was also shown that meadow sward used $58-78 \% \mathrm{~N}$ of the total amount of $\mathrm{N}$ input.
\end{abstract}

Keywords: soil nitrogen, humic alluvial soil, management of mineral nitrogen

Przestano do redakcji: $30.05 .2015 \mathrm{r}$.

Przyjęto do druku: 30.10 .2015 r.

DOI:10.7862/rb.2015.130 